\title{
PROKLA-Redaktion
}

\section{Marx und Keynes}

Die meisten Ökonomen, ebenso wie die meisten Politiker, glauben sowohl Marx als auch Keynes so gut zu kennen, dass eine Auseinandersetzung nicht mehr notwendig sei. Dabei wird aber im wesentlichen ein Schatz von Vorurteilen gepflegt: Marx gilt als Vertreter einer längst überholten und widerlegten Arbeitswerttheorie, die zur Analyse des modernen Kapitalismus unbrauchbar sei, Keynes wird auf eine Wirtschaftspolitik des „Deficit-Spending“ reduziert, von der man wisse, dass sie gescheitert ist. An derart verkürzten Auffassungen sind allerdings die historisch dominierenden Vertreter des „Marxismus“ wie des „Keynesianimus" nicht unbeteiligt sind. Sowohl der traditionelle Marxismus der Arbeiterbewegung (der im „MarxismusLeninismus" seinen dogmatischsten Ausdruck fand) als auch die Vertreter der „keynesianischen“ Wirtschaftspolitik der $60 \mathrm{er}$ und 70er Jahre lieferten nur ein höchst verzerrtes Bild der theoretischen Ansätze von Marx und Keynes. Dass beide die herrschenden ökonomischen Theorien nicht nur in ihren Ergebnissen, sondern bereits in ihrer Grundlagen kritisierten, ging in den popularisierten Auffassungen weitgehend verloren: im traditionellen Marxismus erscheint Marx lediglich als der bessere Vertreter der klassischen politischen Ökonomie, der die Arbeitswerttheorie endlich zum Nachweis der Ausbeutung benutzt; und im Rahmen des sog. IS-LM Modells, das auch heute noch in den meisten Lehrbüchern als „der Keynesianismus“ gilt, schrumpft die Keynessche Theorie auf eine untergeordnete Ergänzung zum nach wie vor gültigen Grundmodell der Neoklassik zusammen.

Parallel zu den immer größeren Problemen, mit denen sowohl linke, einem traditionellen Marxismus verhaftete Parteien als auch die verschiedenen Versuche keynesianischer Reformpolitik zu kämpfen hatten, wurden jedoch seit den 60er und 70er Jahren sowohl das Marxsche wie auch das Keynessche Werk neu diskutiert. Auf einer viel grundlegenderen Ebene wurde nun an die kritischen Intentionen von Marx und Keynes angeknüpft. Dabei wurde auch deutlich, dass Marx wie Keynes - wenn auch in jeweils ganz anderen theoretischen Kontexten - der herrschenden Lehre vorwarfen, in ihren kategorialen Grundbestimmungen vom Geld zu abstrahieren, in dem es lediglich auf seine Funktion als Recheneinheit und Tauschmittel reduziert wird. Durch diese Verkürzung können es sich Klassik wie Neoklassik erlauben, allein „reale“ (also nicht-monetäre) Größen als die für die Ökonomie entscheidenden $\mathrm{zu}$ betrachten. Und erst diese Fiktion einer nicht-monetären Ökonomie macht es dann möglich, den „Beweis“ anzutreten, dass kapitalistische Wirtschaften prinzipiell krisenfrei seien. Dagegen hatte Marx bereits geltend gemacht, dass in der Vermittlung der Wa- 
renzirkulation durch das Geld die allgemeine Möglichkeit der Krise begründet liege.

In den Debatten der 70er und 80er Jahre wurde einerseits der „monetäre“ Charakter der Marxschen Werttheorie herausgearbeitet, andererseits entstanden verschiedene Zweige einer „monetären“ Interpretation der Keynesschen Theorie. Gerade angesichts der Internationalisierung des Finanzsystems in den 70er und 80er Jahren sowie der zunehmenden Finanzkrisen in den 90er Jahren erhalten diese monetären Ansätze eine besondere Relevanz zur Analyse des gegenwärtigen Kapitalismus. Die PROKLA widmete diesen Debatten schon mehrere Hefte (vgl. Nr. 63 Geld, Juni 1986; Nr. 72 Marxismus ohne Marx, September 1988, Nr. 103 Vom Gelde, Juni 1996). Mit dem vorliegenden Heft werden diese Diskussionen fortgesetzt.

Michael Heinrich und Hansjörg Herr unternehmen es in ihren Beiträgen Marx bzw. Keynes gegen die noch immer stark dominierenden traditionellen Interpretationslinien abzugrenzen und das ursprünglich vorhandene kritische Potential herauszuarbeiten. Klaus Dräger diskutiert zwei verschiedene marxistische Analysen der kapitalistischen Nachkriegsentwicklung: er konfrontiert Robert Brenners viel beachtete Studie zu den "Turbulenzen der Weltökonomie" mit dem Ansatz der Regulationsschule. Victoria Chick untersucht von einer postkeynesianischen Position aus verschiedene Zugänge zur Geldtheorie und begründet ihr Konzept einer historisch vermittelten Theoriebildung, das den universalistischen Ansätzen der Neoklassik wie auch eines neoklassisch geprägten Keynesianismus diametral entgegen steht. Bernhard Emunds führt in den „finanzkeynesianischen“ Ansatz von
Hyman P. Minsky und dessen Weiterentwicklung ein. Welche Konsequenzen der Postkeynesianismus für die Finanzpolitik, insbesondere das Problem der Staatsverschuldung hat, wird von Arne Heise diskutiert. Schließlich beschäftigt sich Elke Muchlinski mit einem zentralen Problem der internationalen Währungsbeziehungen, der monetären Koordination der Zentralbanken im tripolaren System von Dollar, Yen und DMark/Euro.

Außerhalb des Schwerpunkts erscheint von Christof Parnreiter ein Reviewartikel zu neuerer Literatur, die sich mit der neoliberalen Transformation in Lateinamerika auseinandersetzt.

$* * *$

Dem Heft ist ein kleiner Fragebogen beigelegt. Die Redaktion möchte damit erfahren, welche Art von Beiträgen für die LeserInnen besonders interessant sind und wie die PROKLA verwendet wird - Informationen, die für die konkrete Gestaltung der PROKLA sehr wichtig wären. Der Verlag möchte mit dem Fragebogen erfahren, auf welchen Wegen die PROKLA in der Öffentlichkeit wahrgenommen wird, um den Vertrieb zu verbessern. Wir bitten möglichst viele LeserInnen den Bogen auszufüllen und an den Verlag zu schicken - als kleiner Anreiz werden unter den Einsendern 10 Bücher verlost. 